\title{
Lise Öğrencilerinin Sosyal Görünüş Kayg1 Düzeylerinin Bazı Değişkenlere Göre İncelenmesi ${ }^{1}$
}

\author{
DOI: 10.26466/opus.523444
}

*

Bünyamin Ceetinkaya*-Fikret Gülaçtt ${ }^{* *}$ - Zeynep Çiftci ${ }^{* * *}$

* Dr. Öğrt. Üyesi, Giresun Üniversitesi, Eğitim Fakültesi, Giresun/Türkiye

E-Posta: bumi55@gmail.com

ORCID: 0000-0001-8435-5885

** Doç. Dr. Erzincan Binali Yıldırım Üniversitesi, Eğitim Fakültesi Erzincan/Türkiye

E-Posta: fgulacti@erzincan.edu.tr

ORCID: 0000-0002-3200-1994

E-Posta: zeynepciftcii@hotmail.com

*** Uzman Psikolojik Danışman, -, Erzincan/Türkiye

ORCID: $\underline{0000-0002-9959-224 X}$

Öz

Bu araştırmada lise öğrencilerinin sosyal görünüş kaygı düzeyleri ile cinsiyet, okul, anne ve baba öğrenim durumları, algılanan sosyo-ekonomik düzey, kardeşler arasındaki doğum sırası, algılanan anne baba tutumu, arkadaş ilişkileri, okul başarısı, fiziksel görünüşün değerlendirmesi ve özgüven düzeyi değişkenleri arasında anlamlı bir fark olup olmadığı araştırılmıştır. Bu amaç doğrultusunda çalışmaya Erzincan İli Refahiye İlçesinde farkl liselere devam etmekte olan 115 (64 klz, 51 erkek) öğrenci katılmıştır. Doğan (2011) tarafından Türkçeye uyarlanan "Sosyal Görünüş Kaygısı Ölçeğgi Ergen Formu" kullanılmıştır. Ayrıca araştırmacı tarafından "Kişisel Bilgi Formu" hazırlanmış ve uygulanmıştır. Bu araştırma tarama modelinde betimsel bir çalışmadır. Verilerin analizinde t-testi ve Tek Yönlü Varyans Analizi kullanılmıştır. Araştırma sonucunda özgüven düzeyine göre sosyal görünüş kaygısı puanları arasında istatistiksel açıdan anlamlı bir fark olduğu görülmüştür. Özgüveni düşük olan öğrencilerin sosyal görünüş kaygısı özgüveni yüksek olan öğrencilerden anlamlı bir şekilde fazladır. Sosyal görünüş kaygısı fiziksel görünüş değerlendirmelerine göre istatistik açıdan anlamlı bir farklılık göstermektedir. Fiziksel görünüşünü, hiç beğenmeyen öğrencilerin sosyal görünüş kaygısı puan ortalamalarının, biraz beğenen, kararsız olan, oldukça beğenen ve çok beğenen öğrencilerin puan ortalamalarından anlamlı şekilde yüksek olduğu görülmüştür. Sosyal görünüş kaygısı arkadaş ilişkilerine göre istatistik açıdan anlaml bir farklılık göstermektedir. Arkadaşlarıyla olan ilişkilerini tanımlamada kararsız olanları ortalamaları, iyi ve çok iyi olarak tanımlayanların ortalamalarından anlamlı şekilde yüksek olduğu görülmüştür. Kalan değişkenlerin anlamlı bir fark göstermediği bulunmuştur.

Anahtar Kelimeler: Lise öğrencileri, Sosyal görünüş kaygısı, sosyal kaygı

\footnotetext{
${ }^{1}$ Bu araştırma 2. Pozitif Psikoloji Kongresinde özet bildiri olarak sunulmuştur.
} 


\title{
An Investigating the Levels of Social Appeaarance Anxiety of High School Students in Terms of Various Variables
}

\begin{abstract}
The study aimed to investigate if there is a significant difference between the anxiety level of high school students and the variables of gender, school, education status of mother and father, perceived socioeconomic status, the birth order among siblings, perceived mother and father attitude, relationship between friends, school success, the evaluation of physical appearance and the level of self-esteem. With this purpose the research has been carried out on 115 high school students (64 girls, 51 boys) who are students from different high schools in the province of Refahiye / Erzincan. Social Appearance Anxiety scale Adolescent From which is translated into Turkish by Doğan (2011) is used. In addition, Personal Information From is prepared and used by the researcher. This investigation is a descriptive research in the scanning model. T-test and simple correlation analyzes have been used to collect the data of the research. The results of the research have been revealed that there is a significant differentiation between the social appearance anxiety and the self-esteem. The students with low self-esteem have much more social appearance anxiety than the students with high sels-esteem. According to the evaluations of physical appearance, social appearance anxiety is indicated a statistically significant difference. It is seen that the average point of students who do not like their physical appearance is significantly higher than the average point of students who likes a little, who is hesitant, who likes much and who likes very much. According to friendship relations social appearance anxiety is indicated a statistically significant difference. The ones whose relationship with their friends is somewhat in defining is statistically higher than the ones who defines as very much and extremely. There is no statistically significant difference between the other variables.
\end{abstract}

Keywords: High school students, Social anxiety, Social appearance anxiety 


\section{Giriş}

Ergenlik dönemi, kişinin kişisel ve sosyal kimlikleri arasındaki dengeyi sağlamaya çalıştığı dönem olmasından dolayı çok önemli bir gelişim çağıdır. Kişinin oluşturacağ 1 "kişisel kimlik" kişinin ömrü boyunca sürdürdüğü kişisel tecrübelerle gelişirken, "sosyal kimlik" ise kişinin sosyal çevresindeki kişilerin durumlara verdiği tepkilerle kişinin algısının ortak bir ürünüdür. Kimliğin oluşumu sürecinde her bir gelişim görevinin başarılı bir şekilde tanımlanmasının çok önemli olduğu dikkate alındığında, kişinin beden imgesini kabul etmesi kimliğinin gelişimi açısından kritik öneme sahiptir.

Ergenlik dönemi, gelişimsel açıdan pek çok değişikliğin yaşandığı bir dönemdir. Ergenler bir taraftan değişikliklere adapte olmaya çalışırken, diğer taraftan önemli bir gelişimsel görev olan kimliğini biçimlendirmeye, kendini kişisel olarak isimlendirmeye gayret eder (Archer, 1989).

Ergenlerin diş görünüşlerindeki değişiklikleri, artan zihinsel kabiliyetleri ve içe bakış kapasiteleri, ergenlerin hafızasını aşırı düzeyde ve olumsuz bir şekilde meşgul eder. Buna ek olarak başkalarının kendileri ve bedenleri hakkındaki algılamalarını dikkate alırlar (Rosenblum ve Lewis, 1999). Bireyin kendini benliğini nasıl algıladığ ettiği benlik kavramı ile açıklanır. Benlik, "kişinin tecrübelerinden çıkartılan düzenlenmiş bir bilişsel yapı olarak da değerlendirilebilmektedir" (Adams, 1995). Bunun yanı sıra kişinin kendi bedeniyle doğrudan ilişkili bazı psikolojik faktörler vardır. Bunlardan birisi de beden imajıdır.

Beden imajı ile ilgili tanımlarına bakıldığında, Cash'a (1989) göre beden imaj1, "bireyin kendi bedeniyle ilgili duygu, düşünce ve algılamalarıdır." Moe'ye (1999) göre beden imajı, "kişinin yalnızca fiziksel görünüşle alakalı olmayıp, çok yönlü psikolojik tecrübeleri de kapsamaktadır." Yani kişinin daha çok kendini ne şekilde gördüğü ile alakalı kişisel bir resmini anlatır. Beden imajı, iki şekilde ifade edilmektedir. Bunlar; "olumlu beden imajı" ve "olumsuz beden imajıdır" (Cash, 2004). Doğan'a (2010) göre olumlu beden imajı, "kişinin bedeninden hoşnut olma durumudur." Olumsuz beden imajı ise "kişinin bedeniyle alakalı olumsuz his, düşünce ve inanca sahip olmasının yanı sıra diğerlerine kıyasla kendisini 
daha az alımlı bulmasını, bedeninden utanmasını ve bedenini kabul etmemesidir." Kişinin sahip olduğu olumsuz bir beden imajı, kişinin sosyal görünüş kaygısı yaşamasına sebep olur.

D1ş görünüş, insanlık tarihi süresince kişilerin yaşamında önemli bir yere sahiptir. Günümüzde de 7 den 70'e her insanın özelliklede gençlerin önemle üzerinde durduğu noktalardan biriside dış görünüş olmuştur.

Dış görünüşe yüklenen anlam ve görünüşle alakalı değerlendirmeler, toplumlarda ön planda olmuştur. İnsanlar günümüzde eskiden olduğundan daha çok kendilerinin ve diğerlerinin görünüşüne çok daha ilgi duyar hale gelmiştir (Kılıç ve Karakuş, 2016). İnsanlar diğer kişiler üzerinde etkileyici bir intiba bırakmak için çabalamaktadırlar (Telli ve Ünal, 2016). Çoğu insan daha çok kendisinde hayranlık uyandıracak ve cazibeli kişilerle etkileşim içinde olmayı isterler (Yousefi, Hassani ve Shokri, 2009). İnsanlar diğerleri üzerinde iyi bir etki bırakmak ister. Kişi eğer diğer kişiler üzerinde iyi bir intiba sağlayamayacağını düşünürse bu onun kaygı yaşamasına sebep olur (Leary ve Kowalski, 1995). Bu kaygı ise sosyal görünüş kaygısı olarak adlandırılmaktadır. Hart ve arkadaşları (2008)'na göre sosyal görünüş kaygısı, "sosyal kaygının bir türü olarak insanların dış görünüşlerinin, diğerleri tarafından değerlendirilirken yaşadıkları kayg1 ve gerginlik" olarak ifade edilmiştir. Çınar ve Keskin (2015) ise sosyal görünüş kaygısını, "insanların, başkaları tarafından kendi fiziki yapılarının değerlendirilmesine karşı hissettikleri tepkidir" şeklinde tanımlamıştır. Kişinin görünüşüne ve beden imajına yönelttiği olumsuz değerlendirmelerin sonucunda sosyal görünüş kaygısı ortaya çıkmaktadır. Birçok bozuklukla birlikte var olan ve kişinin gün içindeki sosyal yaşantısını olumsuz bir şekilde etkileten sosyal görünüş kaygısını Doğan (2009), "kişinin dış görünüşü ile alakalı kendi kaygılarını ve başkalarının onu değerlendirmesi ile ilgili yaşanan kaygılarıdır." şeklinde ifade etmiştir. Hart ve arkadaşlarına (2008) göre ise sosyal görünüş kaygısı kavramı "boy, kilo, kas yapısı gibi genel fiziksel görünüşün ötesinde bireyin ten rengi ve yüz şekli (burnu, gözlerinin uzaklığı, gülüşü vs.) gibi özellikleri de içeren daha kapsamlı bir kavramdır." Doğan'a (2010) göre "genel diş görünüşün ötesinde daha kapsamlı ve bütüncül bir durum söz konusudur." Sosyal görünüş kaygısı, esasen kişilerin bedenleriyle ve diş görünüşleriyle alakalı olumsuz olarak algıladıkları beden imajlarının sonucunda ortaya çıkmaktadır. Bu çalışmada da lise öğrencilerinin, 
çalışmada ele alınan bazı değişkenlere göre sosyal görünüş kaygı düzeyleri belirlenmeye çalışılmıştır.

\section{Yöntem}

Araştırmanın Modeli Bu araştırmada betimsel bir çalışma ile lise öğrencilerinin sosyal görünüş kaygı düzeyleri ile cinsiyet, okul, anne ve baba öğrenim durumları, algılanan sosyo-ekonomik düzey, kardeşler arasındaki doğum sırası, algılanan anne baba tutumu, arkadaş ilişkileri, okul başarısı, fiziksel görünüşün değerlendirmesi ve algıladıkları özgüven düzeyi değişkenleri açısından incelenmiştir. Araştırma genel tarama modellerinden İlişkisel tarama modeli ile gerçekleştirilmiştir. İlişkisel Tarama Modelleri, iki ve daha çok sayıdaki değişken arasında değişim varlığını ve/veya derecesini belirlemeyi amaçlayan çalışmalarıdır (Karasar, 1995:85).

Araştırma Grubu: Araştırmanın çalışma grubunu, Erzincan İli Refahiye İlçesinde farklı liselere devam etmekte olan 115 (64 kız, 51 erkek) öğrenci katılmıştır. Araştırmada örnekleme tekniklerinden, küme örnekleme tekniği (oransız küme örnekleme) kullanılmıştır. Bu tekniğe göre, evrenden seçilecek kümeler üzerinde araştırma yapılabilir. Küme örnekleme tekniği evrendeki bütün kümelerin tek tek (bütün elemanlarıyla birlikte) eşit seçilme şansına sahip oldukları örnekleme tekniğidir (Karasar, 1995:114-115). Çalışmayı yapmak için Refahiye'deki tüm liselerin listesi çıkarılmış, bu listeden yansızlık kuralına göre yeterli sayıda lise örnekleme alınmıştır. Alınan liselerdeki tüm örencilerden gönüllü olanları üzerinde çalışma yürütülmüş ve Refahiye'deki tüm lise öğrencileri için genellenmiştir.

\section{Veri Toplama Araçları}

Sosyal Görünüş Kaygısı Ölçeği (SGKÖ): Hart ve arkadaşları (2008) tarafından geliştirilen "Sosyal Görünüş Kaygisı Ölçeği” Doğan (2010) tarafından Türkçeye uyarlanmıştır. Ölçek 16 maddeden oluşmaktadır. “Çok sık:5, Sıkça:4, Bazen:3, Neredeyse hiç:2 ve Hiç:1" şeklinde olmak üzere 5'li likert tipindedir. "Ölçekten alınan puanların ortalaması 
yükseldikçe kaygı düzeyi artmakta, ortalama düştükçe kaygı düzeyi düşmektedir." Ölçeğin 1. maddesi olumsuz olduğundan ters kodlanarak işleme tabi tutulmuştur. Ölçeğin Cronbach Alpha iç tutarlılık katsayısı, bu çalışma kapsamında $\alpha=, 932$ olarak hesaplanmıştır.

Kişisel Bilgi Formu Bu formda öğrencilerden cinsiyet, okul, anne ve baba öğrenim durumları, arkadaşlık ilişkileri, algılanan özgüven düzeyi, algıladıkları fiziksel görünüşleri, algıladıkları okul başarı düzeyleri, algılanan sosyo-ekonomik düzey, kardeşler arasındaki doğum sırası, algılanan anne baba tutumu değişkenleri verileri toplanacak şekilde form oluşturulmuştur.

\section{Verilerin Analizi}

Araştırmanın veri analizi kısmında SPSS 21.0 İstatistiksel analiz programı kullanılmıştır. Bu kapsamda, araştırmada elde edilen bilgiler bilgisayar ortamına girilmiş ve "Bağımsız Gruplar t testi, Tek yönlü Varyans analizleri (ANOVA)" yapılarak istatistiksel sonuçlara ulaşılmıştır.

\section{Bulgular}

Tablo 1. Cinsiyete Göre Sosyal Görünü̧ş Kaygısı Puanlarna İlişkin Bağımsız Örneklemler için t- Testi Sonuçlarn

\begin{tabular}{|c|c|c|c|c|c|c|}
\hline Cinsiyet & $\mathrm{N}$ & $\bar{X}$ & $S$ & $\mathrm{Sd}$ & $\mathrm{t}$ & $\mathrm{p}$ \\
\hline Kadın & 64 & 37.96 & 14,45 & 113 & 1,272 & 206 \\
\hline Erkek & 51 & 34.62 & 13,39 & & & \\
\hline
\end{tabular}

p $>05$

Tablo 1'de görülen bağımsız örneklemler için t-testi sonucunda göre kadınların sosyal görünüş kaygısı puanları ile erkeklerin puanları anlamlı bir şekilde farklılaşmamaktadır (t $(113)=1,272, \mathrm{p}>.05)$.

Tablo 2. Algıladıkları Özgüven Düzeyine Göre Sosyal Görünüş Kaygısı Puanlarına İlişkin Bağımsız Örneklemler için t-Testi Sonuçları

\begin{tabular}{|c|c|c|c|c|c|c|}
\hline Özgüven & $\mathrm{N}$ & $\bar{X}$ & $S$ & $\mathrm{Sd}$ & $\mathrm{t}$ & $p$ \\
\hline Yüksek & 82 & 34,51 & 13,45 & 113 & $-2,429$ &, $017^{*}$ \\
\hline Düşük & 33 & 41,39 & 14,45 & & & \\
\hline
\end{tabular}
$p<.05$ 
Tablo 2'de görülen bağımsız örneklemler için t-testi sonucunda özgüven düzeyine göre sosyal görünüş kaygisı puanları anlamlı bir şekilde farklılaşmaktadır ( $t(113)=-2,429, p<.05)$. Özgüveni düşük olan öğrencilerin sosyal görünüş kaygısı özgüveni yüksek olan öğrencilerden anlamlı bir şekilde fazladır.

Tablo 3. Fiziksel Görünüş Değerlendirmelerine Göre Sosyal Görünüş Kaygısı Puanlarına İlişkin Tek Yönlï ANOVA Sonuçları

\begin{tabular}{|c|c|c|c|c|c|}
\hline \multirow[t]{2}{*}{ Varyans Kaynağ 1} & \multirow{2}{*}{$\begin{array}{l}\text { Kareler } \\
\text { Toplamı }\end{array}$} & \multicolumn{3}{|c|}{ Ortalama } & \multirow[b]{2}{*}{$\mathrm{p}$} \\
\hline & & $\mathrm{Sd}$ & Kare & $\mathrm{F}$ & \\
\hline Gruplar Arası & 4027,288 & 4 & 1006,822 & 6,009 &, $000^{* *}$ \\
\hline Gruplar İçi & 18431,442 & 110 & 167,559 & & \\
\hline Toplam & 22458,730 & 114 & & & \\
\hline
\end{tabular}

Tablo 3'te görülen Tek Yönlü ANOVA sonuçlarına göre sosyal görünüş kaygısı fiziksel görünüş değerlendirmelerine göre istatistik açıdan anlamlı bir farklılık göstermektedir $(\mathrm{F}=6,00, \mathrm{p}<.01)$. Farklılı̆̆ın hangi grup arasında olduğunu saptamak amacıyla LSD testi uygulanmıştır. LSD testi sonucunda, Fiziksel görünüşünü, Hiç beğenmeyen (Ort = 49,1429) öğrencilerin sosyal görünüş kaygısı puan ortalamalarının, Biraz beğenen (Ort = $38,2121)$, Kararsız olan (Ort $=37,3333)$, Oldukça beğenen $($ Ort $=31,2609)$ ve Çok beğenen $(\mathrm{Ort}=28,8889)$ öğrencilerin puan ortalamalarından anlamlı şekilde yüksek olduğu görülmüştür. Fiziksel görünüşünü Biraz beğenen (Ort $=38,2121)$ ve Fiziksel görünüşü hakkında kararsız olan öğrencilerin (Ort $=37,3333$ ) sosyal görünüş kaygısı puan ortalamaları Çok beğenen (Ort $=37,3333$ ) öğrencilerin puan ortalamalarından anlamlı şekilde fazladır. Aynı zamanda diğer fiziksel görünüş grupları arasında anlamlı bir farklılık yoktur.

Tablo 4. Arkadaşlık İlişkilerine Göre Sosyal Görünüş Kaygısı Puanlarına İlişkin Tek Yönlü ANOVA Sonuçları

\begin{tabular}{|c|c|c|c|c|c|}
\hline Varyans Kaynağ 1 & Kareler Toplamı & $\mathrm{Sd}$ & Ortalama Kare & $\mathrm{F}$ & $\mathrm{p}$ \\
\hline Gruplar Arası & 3102,576 & 3 & 1034,192 & 5,931 &, $001^{*}$ \\
\hline Gruplar İçi & 19356,154 & 111 & 174,380 & & \\
\hline Toplam & 22458,730 & 114 & & & \\
\hline
\end{tabular}
$p<.05^{*}$ 
Tablo 4'te görülen Tek Yönlü ANOVA sonuçlarına göre sosyal görünüş kaygısı arkadaşlık ilişkileri değerlendirmelerine göre istatistik açıdan anlamlı bir farklılık göstermektedir $(F=5,93, p<.05)$. Farklılığın hangi grup arasında olduğunu saptamak amacıyla LSD testi uygulanmıştır. LSD testi sonucunda arkadaşlık ilişkilerini kararsız olarak değerlendiren (Ort $=42,0909$ ), öğrencilerin sosyal görünüş kaygısı puan ortalamalarının arkadaşlık ilişkilerinde iyi olarak değerlendirenlerden $(O r t=40,5000)$ ve çok iyi olarak $(O r t=30,5102)$ değerlendiren öğrencilerin puan ortalamalarından anlamlı şekilde yüksek olduğu görülmüştür.

Tablo 5. Anne Eğitim Düzeylerine Göre Sosyal Görünüş Kaygısı Puanlarına İlişkin Tek Yönlü ANOVA Sonuçlan

\begin{tabular}{|c|c|c|c|c|c|}
\hline \multirow[t]{2}{*}{ Varyans Kaynağ 1} & \multirow{2}{*}{$\begin{array}{l}\text { Kareler } \\
\text { Toplamı }\end{array}$} & \multicolumn{3}{|c|}{ Ortalama } & \multirow[b]{2}{*}{$\mathrm{p}$} \\
\hline & & $\mathrm{Sd}$ & Kare & $\mathrm{F}$ & \\
\hline Gruplar Arası & 1041,951 & 5 & 208,390 & 1,061 & 386 \\
\hline Gruplar İçi & 21416,780 & 109 & 196,484 & & \\
\hline Toplam & 22458,730 & 114 & & & \\
\hline
\end{tabular}

Tablo 5'te görülen Tek Yönlü ANOVA sonuçlarına göre sosyal görünüş kaygısı anne öğrenim durumu değişkenine göre istatistik açıdan anlamlı bir şekilde farklılaşmamaktadır $(F=1,061, p>.05)$.

Tablo 6. Baba Eğitim Düzeylerine Göre Sosyal Görünüş Kaygısı Puanlarına İlişkin Tek Yönlü ANOVA Sonuçları

\begin{tabular}{|c|c|c|c|c|c|}
\hline Varyans & Kareler & & Ortalama & & \\
\hline Kaynağ1 & Toplamı & $\mathrm{Sd}$ & Kare & $\mathrm{F}$ & $\mathrm{p}$ \\
\hline $\begin{array}{l}\text { Gruplar } \\
\text { Arası }\end{array}$ & 1036,140 & 5 & 207,228 & 1,054 & 390 \\
\hline Gruplar İçi & 21422,590 & 109 & 196,538 & & \\
\hline Toplam & 22458,730 & 114 & & & \\
\hline
\end{tabular}

Tablo 6'da görülen Tek Yönlü ANOVA sonuçlarına göre sosyal görünüş kaygısı baba öğrenim durumu değişkenine göre istatistik açıdan anlamlı bir farklılık göstermemektedir $(F=1,054, p>.05)$. 
Tablo 7. Okul Değişkenine Göre Sosyal Görünüş Kaygısı Puanlarına İlişkin Tek Yönlü ANOVA Sonuçları

\begin{tabular}{|c|c|c|c|c|c|}
\hline Varyans & Kareler Top- & & Ortalama & & \\
\hline Kaynağ & lamı & $\mathrm{Sd}$ & Kare & $\mathrm{F}$ & $\mathrm{p}$ \\
\hline $\begin{array}{l}\text { Gruplar } \\
\text { Arası }\end{array}$ & 918,861 & 2 & 459,431 & 2,389 & ,096 \\
\hline Gruplar İçi & 21539,869 & 112 & 192,320 & & \\
\hline Toplam & 22458,730 & 114 & & & \\
\hline
\end{tabular}

Tablo 7'de görülen Tek Yönlü ANOVA sonuçlarına göre sosyal görünüş kaygısı okul türüne göre istatistik açıdan anlamlı bir farklılık göstermemektedir $(F=2,389, p>.05)$.

Tablo 8. Kardeş Sırası Değişkenine Göre Sosyal Görünüş Kaygısı Puanlarına İlişkin Tek Yönlü ANOVA Sonuçlan

\begin{tabular}{|c|c|c|c|c|c|}
\hline Varyans & Kareler & & Ortalama & & \\
\hline Kaynağ1 & Toplamı & $\mathrm{Sd}$ & Kare & $\mathrm{F}$ & $\mathrm{p}$ \\
\hline $\begin{array}{l}\text { Gruplar } \\
\text { Arasi }\end{array}$ & 367,109 & 3 & 122,370 & 615 & ,607 \\
\hline Gruplar İçi & 22091,621 & 111 & 199,024 & & \\
\hline Toplam & 22458,730 & 114 & & & \\
\hline
\end{tabular}

Tablo 8'de görülen Tek Yönlü ANOVA sonuçlarına göre sosyal görünüş kaygısı kardeş sırasına göre istatistik açıdan anlamlı bir farklılık göstermemektedir $(F=, 615, p>$.05).

Tablo 9. Algılanan Sosyo-ekonomik Durum Değişkenine Göre Sosyal Görünüş Kaygısı Puanlarına İlişkin Tek Yönlü ANOVA Sonuçları

\begin{tabular}{|c|c|c|c|c|c|}
\hline Varyans & Kareler & & Ortalama & & \\
\hline Kaynağ1 & Toplamı & $\mathrm{Sd}$ & Kare & $\mathrm{F}$ & $\mathrm{p}$ \\
\hline $\begin{array}{l}\text { Gruplar } \\
\text { Arasi }\end{array}$ & 283,465 & 2 & 141,732 & ,716 & ,491 \\
\hline Gruplar İçi & 22175,265 & 112 & 197,993 & & \\
\hline Toplam & 22458,730 & 114 & & & \\
\hline
\end{tabular}


Tablo 9'da görülen Tek Yönlü ANOVA sonuçlarına göre sosyal görünüş kaygısı algılanan sosyo-ekonomik durum değişkenine göre istatistik açıdan anlamlı bir farklılık göstermemektedir $(F=, 716, p>.05)$.

Tablo 10. Algılanan Anne-Baba Tutumuna Göre Sosyal Görünüş Kaygısı Puanlarına İlişkin Tek Yönlü ANOVA Sonuçlarn

\begin{tabular}{|c|c|c|c|c|c|}
\hline Varyans & Kareler & & Ortalama & & \\
\hline Kaynağ1 & Toplamı & $\mathrm{Sd}$ & Kare & $\mathrm{F}$ & $\mathrm{p}$ \\
\hline $\begin{array}{l}\text { Gruplar } \\
\text { Arası }\end{array}$ & 443,282 & 3 & 147,761 & ,745 & ,527 \\
\hline Gruplar İçi & 22015,448 & 111 & 198,337 & & \\
\hline Toplam & 22458,730 & 114 & & & \\
\hline
\end{tabular}

Tablo 10'da görülen Tek Yönlü ANOVA sonuçlarına göre sosyal görünüş kaygısı algılanan anne-baba tutumuna göre istatistik açıdan anlamlı bir farklılık göstermemektedir $(F=, 745, p>.05)$.

Tablo 11. Algılanan Okul Başarısına Göre Sosyal Görünüş Kaygısı Puanlarına İlişkin Tek Yönlü ANOVA Sonuçları

\begin{tabular}{|c|c|c|c|c|c|}
\hline Varyans & Kareler & & Ortalama & & \\
\hline Kaynağ1 & Toplamı & $\mathrm{Sd}$ & Kare & $\mathrm{F}$ & $\mathrm{p}$ \\
\hline $\begin{array}{l}\text { Gruplar } \\
\text { Arası }\end{array}$ & 1512,873 & 4 & 378,218 & 1,986 & ,102 \\
\hline Gruplar İçi & 20945,857 & 110 & 190,417 & & \\
\hline Toplam & 22458,730 & 114 & & & \\
\hline
\end{tabular}

Tablo 11'de görülen Tek Yönlü ANOVA sonuçlarına göre sosyal görünüş kaygısı algılanan okul başarısına göre istatistik açıdan anlamlı bir farklılık göstermemektedir $(F=1,986, p>.05)$.

\section{Tartışma, Sonuç}

$\mathrm{Bu}$ bölümde, lise öğrencilerinin sosyal görünüş kaygı düzeyleri ile cinsiyet, okul, anne ve baba öğrenim durumları, algılanan sosyoekonomik düzey, kardeşler arasındaki doğum sırası, algılanan anne baba 
tutumu, arkadaş ilişkileri, okul başarısı, fiziksel görünüşün değerlendirmesi ve algıladıkları özgüven düzeyi değişkenleri açısından bir farklılık yaratıp yaratmadığına ilişkin bulgular tartışılmış ve önerilerde bulunulmuştur.

Bu çalışmada sosyal görünüş kaygısının cinsiyete göre anlamlı bir şekilde farklılaşmadığı görülmüştür. Bu araştırma bulguları daha önce Türkiyede farklı gelişim dönemlerindeki ergenler üzerinde gerçekleştirilen çok sayıda araştırma sonucuyla benzerlik göstermektedir (Çakmak, 2018; Dinç Altun (2016), Amil ve Bozgeyikli, 2015; Yüceant, 2013). Diğer yandan kadınların erkeklerden daha yüksek sosyal görünüş kaygısına sahip olduğunu bulan araştırmacılarda vardır (Hagger ve Stevenson, 2010; Alımcı, 2018). Erkeklerin kadınlardan daha yüksek sosyal görünüş kaygısı düzeylerine sahip olduğunu gösteren araştırmalarda bulunmaktadır (Tiegman, 2004; Moreno ve Cervello, 2005; Alemdağ, 2013; Kılıç ve Karakuş 2016).

Araştırma sonucunda özgüven düzeyine göre sosyal görünüş kaygısı puanları arasında istatistiksel açıdan anlamlı bir fark olduğu görülmüştür. Özgüveni düşük olan öğrencilerin sosyal görünüş kaygısı özgüveni yüksek olan öğrencilerden anlamlı bir şekilde fazladır. Araştırma bulgusu Dinç Altun (2016)'un bulguları ile örtüşmektedir. Sosyal görünüş kaygısı fiziksel görünüş değerlendirmelerine göre istatistik açıdan anlamlı bir farklılık göstermektedir. Fiziksel görünüşünü, hiç beğenmeyen öğrencilerin sosyal görünüş kaygısı puan ortalamalarının, biraz beğenen, kararsız olan, oldukça beğenen ve çok beğenen öğrencilerin puan ortalamalarından anlamlı şekilde yüksek olduğu görülmüştür. Dinç Altun (2016) tarafından yapılan çalışmada da fiziksel görünüşünü algılama düzeyi ile sosyal görünüş kaygısı puanları arasında ilişki saptanmıştır. Ayrıca sosyal görünüş kaygısının algılanan olumsuz beden imajından kaynaklandığı sonucuna ulaşan çalışmada vardır (Doğan, 2010).

Sosyal görünüş kaygısı arkadaş ilişkilerine göre istatistik açıdan anlamlı bir farklılık göstermektedir. Arkadaşlarıyla olan ilişkilerini tanımlamada kararsız olanların ortalamaları, iyi ve çok iyi olarak tanımlayanların ortalamalarından anlamlı şekilde yüksek olduğu görülmüştür.

Araştırmada anne babanın öğrenim durumlarının sosyal görünüş kaygısı ile anlamlı fark ortaya koymadığı bulunmuştur. Bu sonuç Şahin, 
Barut ve Ersanlı (2013) ve Dinç Altun (2016) yaptıkları araştırma bulguları ile örtüşmemektedir. Yapılan araştırmada sosyal görünüş kaygısı kardeş sırasına göre istatistik açıdan anlamlı bir şekilde farklılaşmamıştır. Dinç Altun (2016) tarafından yapılan çalışmanın bulguları bizim çalışmamızın sonucuyla benzerlik göstermektedir.

Araştırma sonucunda sosyal görünüş kaygısı, algılanan anne-baba tutumuna göre istatistiksel açıdan anlamlı bir farklılık göstermemektedir. Dinç Altun (2016) tarafından yapılan çalışmanın bulguları bizim çalışmamızın sonucuyla örtüşmemektedir. Demokratik anne-baba tutumuna sahip bireylerin sosyal görünüş kaygısı diğer anne- baba tutumuna sahip bireylerden anlamlı şekilde daha düşüktür.

Yapılan araştırmada sosyal görünüş kaygısı algılanan okul başarısına göre istatistik açıdan anlamlı bir farklılık göstermemektedir. Dinç Altun (2016); Alemdağ (2013) ve Işıkol-Özge (2013) tarafından yapılan çalışmaların bulguları bizim çalışmamızın sonucuyla örtüşmemektedir.

\section{Öneriler}

- Özgüveni düşük, fiziksel görünüşünü beğenmeyen öğrenciler için okullarda bulunan Rehberlik servisleri tarafindan okul Psikolojik Danışmanlarınca özgüven artırmaya yönelik çalışmalar yapılabilir.

- Okul rehberlik servislerinde görev yapan Psikolojik Danışmanlar tarafından özellikle ergenlik döneminde olan ve ergenlik sonrası dönemdeki lise öğrencilerinin sosyal görünüş kaygısını azaltmaya yönelik etkinlikler planlanabilir ve grup rehberliği çalışmaları geliştirilebilir.

- Yine okullarda Rehberlik servisleri tarafından öğrencilerin kendileriyle barışık olmaları ve kendini kabul düzeylerini yükseltmeye yönelik çalışmalar yapılabilir.

- Bir ilçe merkezinde ve belirli sayıda lise öğrencisiyle yapılmış olan bu çalışmanın çok daha farklı yerlerde ve daha çok sayıda yapılması, daha geniş örneklem gruplarıla yapılarak elde edilecek sonuçların Milli Eğitim Bakanlı̆̆ Özel eğitim rehberlik ve danışma hizmetleri genel müdürlügünce değerlendirmeye alınarak okullarda genele yönelik çalışmalar planlanması sağlanabilir. 


\title{
EXTENDED ABSTRACT
}

\section{An Investigating the Levels of Social Appeaarance Anxiety of High School Students in Terms of Various Variables}

\author{
Bünyamin Çetinkaya - Fikret Gülaçtı - Zeynep Çiftçi \\ Giresun University - Erzincan Binali Yaldırm University - Ministry of National Education
}

Adolescence is a very important period of development because it is the period when a person tries to balance between their personal and social identities. Considering that it is very important to successfully identify each development task in the process of identity formation, accepting the body image is critical for the development of identity.

Adolescence is a period in which many changes are experienced developmentally. Adolescents try to adapt to changes on the one hand, it tries to shape its identity, which is an important developmental task, to name itself personally (Archer, 1989). Adolescents' changes in their external appearance, their increased mental abilities, and their ability to look inwardly interfere with the memory of adolescents, and also take into account the perceptions of others about themselves and their bodies (Rosenblum and Lewis, 1999).How the individual perceives his/her self and how he analyzes himself/herself is explained by the concept of self.

Self can also be considered as a "regulated cognitive structure derived from one's experiences"(Adams, 1995). In addition, there are some psychological factors that are directly related to one's own body. One of them is the body image.

According to Cash" (1989), body image is related with individual's feelings, thoughts and perceptions about his / her own body. "According to Moe (1999), the image of the body is not only related to the physical appearance of the person, but also to the multidimensional psychological experiences. Body image is expressed in two ways. These are positive body image "and negative body image" (Cash, 2004). 
According to Doğan (2010), the positive body image is the state of being satisfied with the body of the person. Negative body image is not only having negative feelings, thoughts and beliefs related to one's body, but also finding himself less attractive than others and not accepting his body and ashamed of his body.

A negative body image of the person causes the person to have a social appearance anxiety. People have become much more interested in the appearance of themselves and others than they used to be today (Kılıç and Karakuş, 2016). People are striving to leave an impressive impression on other people. (Telli and Unal, 2016). Most people want to interact with attractive and fascinated people (Yousefi, Hassani and Shokri, 2009).

People want to leave a good impression on others. If he thinks that he cannot have a good impression on other people, this causes him to have anxiety (Leary and Kowalski, 1995).

This anxiety is called as social appearance anxiety. According to Hart, Flora, Palyo, Fresco, Holle, and Heimberg (2008), the social appearance anxiety was expressed as, the anxiety and tension of the external appearance of people as a type of social anxiety when evaluated by others.

Çınar and Keskin (2015) defined social anxiety as the reaction of people to the evaluation of their physical structure by others. The concern for social appearances is the result of body images that are perceived as negative by their bodies and their appearance. In this study, social appearance anxiety levels of high school students were investigated according to some variables.

In this study, social appearance anxiety levels of high school students is examined in terms of gender, school, mother and father education status, perceived socio-economic level, birth order among siblings, perceived parental attitude, friend relations, school success, physical appearance assessment and perceived self-confidence level with a descriptive study. The research was carried out with relational screening model from the general survey models (Karasar, 1995: 85). The study group is 115 (64 female, 51 male) students who are attending different high schools in Refahiye District of Erzincan Province. 
In this study, cluster sampling technique (disproportionate cluster sampling) was used. According to this technique, research can be carried out on clusters selected from the universe (Karasar, 1995: 114-115). Social Appearance Anxiety Scale which was developed by Hart et al. (2008) and adapted to

Turkish by Doğan (2010) was used. The Personal Information Form developed by the researchers was also used. SPSS 21.0 Statistical analysis program was used in data analysis and, Independent Groups t test, Oneway Variance Analysis (ANOVA) were performed.

According to the results of the study, there was a statistically significant difference between the self- confidence level and the social appearance anxiety scores. Students who have low self-esteem have more social appearance anxiety than students with high self-esteem. The findings of the study are similar to those of Dinç Altun (2016). Social appearance anxiety shows a statistically significant difference according to physical appearance evaluations.

Students who did not like their physical appearance were significantly higher in their social appearance anxiety scores than the ones who were a little likable, unstable, very liking and very liking. Dinç Altun (2016) presents similar results. At the same time, there is a study that concludes that social appearance anxiety is due to perceived negative body image (Doğan, 2010).

Social appearance anxiety shows a statistically significant difference according to friend relations. The average of the ones who were unstable in defining their relationships with their friends were found to be significantly higher than those who defined them as good and very good. As a result of this study, it was seen that social appearance anxiety did not differ significantly according to gender. These research findings, many are similar to the results of research carried out on those previously adolescents in different developmental stages in Turkey (Cakmak, 2018; Dincer Altun (2016), Amylin and Bozgeyikl of 2015; Yüceant, 2013).

On the other hand, there are studies showing that women have higher social appearance anxiety than men (Acquirer, 2018) and that men have higher social appearance anxiety levels than women(Alemdağ, 2013; Kılıç and Karakuş 2016). 
In the study, it was found that the education level of the parents did not reveal any significant difference with the social appearance anxiety. This result is similar to the findings of Şahin, Barut and Ersanlı (2013) and Dinç Altun (2016). In the study, the social appearance anxiety did not differ significantly according to the sibling order. This result is similar to the results of the study of Dinç Altun (2016). As a result of the study, social appearance anxiety did not show a statistically significant difference according to perceived parental attitude. This result is similar to the results of the study of Dinç Altun (2016). Individuals with democratic parental attitudes have a significantly lower social appearance anxiety than those with other parental attitudes.

In the study, social appearance anxiety did not show a statistically significant difference according to perceived school success. However, this result does not coincide with the results of the studies performed by Dinç Altun (2016), Alemdağ (2013) and Işıkol-Özge (2013).

- For the students who do not like their physical appearances and have low self-confidence, the school Psychological Counselors can prepare activities to increase their self-esteem.

- Psychological counselors working in school guidance services can plan activities and group guidance activities to reduce the social appearance anxiety of adolescents and adolescents in post-adolescent period.

- In schools, guidance services can help students to be at peace with themselves and raise their level of self-acceptance.

\section{Kaynakça / References}

Adams, J. F. (1995), Ergenliği anlamak, Ankara: İmge yayınları.

Alemdağ, S. (2013). Öğretmen adaylarında fiziksel aktiviteye katılım, sosyal görünüş kaygısı ve sosyal öz-yeterlik ilişkisinin incelenmesi. Yayımlanmamış doktora tezi. Karadeniz Teknik Üniversitesi, Trabzon. 
Alımcı, D. (2018). Ortaokul öğrencilerinin akran zorbahı̆g ve sosyal görünüş kaygıları ile kendine saygıları arasındaki ilişkinin incelenmesi. Yayımlanmamış yüksek lisans tezi. İstanbul Sabahattin Zaim Üniversitesi, İstanbul.

Amil, O. ve Bozgeyikli, H. (2015). Investigating the relationship between social appearance anxiety and loneliness of turkish university youth. Journal of Studies in Social Sciences, 11(1), 68-96.

Archer, S. L. (1989), The status of 1dentity: Reflections on the weed for intervention, Journal of Adolescent, 12, 345-359

Cash T. F. (1989). Body-image affect: Gestalt versus summing the parts. Perceptual and Motor Skills, 69, 17-18.

Cash, T. F. (2004). Body image: Past, present and future, body image. $A n$ International Journal of Research, 1, 1-5.

Çakmak, E. (2018). Üniversite öğrencilerinin sosyal medya kullanım düzeyleri ile sosyal görünüş kaygısı arasındaki ilişkinin farkh değişkenler açısından değerlendirilmesi. Yayımlanmamış yüksek lisans tezi. Beykent Üniversitesi, İstanbul.

Çınar, H. ve Keskin, N. (2015). Öğrencilerin sosyal görünüş kaygısının öğrenim yeri tercihlerine etkisi. Electronic Journal of Vocational Colleges, 14, 457-465.

Dinç Altun, M. (2016). Lise öğrencilerinin sosyal görünüş kaygıları. Yayımlanmamış yüksek lisans tezi. On dokuz Mayıs Üniversitesi, Samsun.

Doğan, T. (2010). Sosyal Görünüş Kaygısı Ölçeği'nin (SGKÖ) Türkçe uyarlaması: Geçerlik ve güvenirlik çalışması. Hacettepe Üniversitesi Ĕ̆itim Fakültesi Dergisi, 39(39), 151-159.

Doğan, T. (2009). Bilişsel ve kendini değerlendirme süreçlerinin sosyal anksiyete açısından incelenmesi. Yayımlanmamış doktora Tezi, Sakarya Üniversitesi, Sakarya.

Hagger, S. Martin ve Stevenson, Andy (2010). Social physique anxiety and physical self-esteem: Gender and age effects. Psychol and Health, 25, No.1, (89-110).

Hart, T. A., Flora, D. B., Palyo, S. A., Fresco, D. M., Holle, C. ve Heimberg, R. G. (2008). Development and examination of ehe social appearance anxiety scale. Assessment, 15(1), 48-59. doi: 10.1177/1073191107306673 
Işıkol-Özge, F. (2013). İlköğretim II. kademe öğrencilerinin sosyal görünüş kaygılarn ile benlik saygıları arasındaki ilişkinin incelenmesi (Üsküdar ilçesi örneği). Yayımlanmamış yüksek lisans tezi. Yeditepe Üniversitesi, İstanbul.

Karasar, N. (1995). Bilimsel araştırma yöntemi, Ankara: 3A Araştırma Eğitim Danışmanlık Ltd.

Kılıç, M. ve Karakuş, Ö. (2016). Üniversite öğrencilerinin sosyal görünüş kaygıları ile benlik saygıları ve yalnızlık düzeyleri arasındaki ilişkinin incelenmesi. Journal of Human Sciences, 13(3), 3837-3852. doi:10.14687/jhs.v13i3.4054

Leary, M. R. ve Kowalski, R. M. (1995). Social anxiety, Guilford: New York. Moe, B. (1999). Understanding the causes of a negative body imaje. Newyork: The Rozen Publishing Group, Inc.

Moreno, J. A. ve Cervelló, E. (2005). Physical self-perception in spanish adolescents: Effects of gender and involvent in physical activity. Journal of Human Movement Studies, 48, 291-311.

Rosenblum, G. D. ve Lewis, M. (1999). The relations among body image, physical attractiveness, and bady mass in adolescence, Child Development,70, 50-64.

Şahin, E., Barut, Y. ve Ersanlı, E. (2013). Sociodemographic variables in relation to social appearance anxiety in adolescents. The International Journal of Social Sciences, 15 (1), 56-63

Telli, E. ve Ünal, Z. (2016). Üniversite öğrencilerinin sosyo-demografik özelliklerine göre sosyal görünüş kaygısı: Bir alan araştırması. Mehmet Akif Ersoy Üniversitesi Sosyal Bilimler Enstitüsü Dergisi, 8(15), 134-146.

Tiegman, M. (2004). Body image across the adult life span: Stability and change. Body Image, 1 (1); 29-41.

Yousefi, B., Hassani, Z. ve Shokri, O. (2009). Reliability and factor validity of the 7- Item Social Physique Anxiety Scale (SPAS-7) among university students in Iran. World Journal of Sport Sciences 2, Number. 3, 201-204.

Yüceant, M. (2013). Beden eğitimi öğretmen adaylarının sosyal görünüş kayg̨larının farklı değişkenler açısından incelenmesi. Yayımlanmamış yüksek lisans tezi. Aksaray Üniversitesi, Aksaray. 


\section{Kaynakça Bilgisi / Citation Information}

Çetinkaya, B., Gülaçtı, F. ve Çiftci, Z. (2019). Lise öğrencilerinin sosyal görünüş kaygı düzeylerinin bazı değişkenlere göre incelenmesi. OPUS-Uluslararası Toplum Araştırmaları Dergisi , 10(17), 904-922. DOI: 10.26466/opus.523444 